\title{
Which Surgical Strategy in Sepsis from Retro Peritoneal Colic Perforation
}

\author{
Graziano Giorgio Maria Paolo*, Buffone Antonino and Graziano Antonino \\ Medical School University of Catania, Italy
}

*Corresponding author: Graziano Giorgio Maria Paolo, Department of Sciences, Medical of surgery and technology advanced “G Ingrassia” Medical School University of Catania Via S Sofia 78 Cap 95215 Catania, Italy

\section{ARTICLE INFO}

Received: 幽 August 28, 2019

Published: 幽 September 11, 2019

Citation: Graziano Giorgio M P, Buffone A, Graziano A. Which Surgical Strategy in Sepsis from Retro Peritoneal Colic Perforation. Biomed J Sci \& Tech Res 21(2)2019. BJSTR. MS.ID.003581.

Keywords: Surgery; Abdominal Infections management
ABSTRACT

Introduction: In the last decade, attention has been paid to severe abdominal infections which, due to their severity and difficulty in treatment, cause death in 30-60\% of cases [1-6]. In this article the surgical strategies in abdominal infections due to colonic perforation are discussed.

Materials and Methods: The study was carried out on 12 patients from January 01.01.2015 to December 31.12.2018 consulting in retrospect the Database and medical records of 'AOU Policlino University of Catania. Department of Medical Surgical Specialties II. In the selection of patients undergoing surgery for retro peritoneal intestinal perforation n 10 cases affected the colorectal, n 2 ileum cases, Patients n 8 were male, and the remaining 4 cases were female with an average age of 62 years [7-61].

Result: Alongside the known advantages of the minimally invasive approach (20\% of cases treated) such as less postoperative pain, shorter hospital stays, less morbidity, in cases of acute abdomen the possibility of avoiding at first was considered instance the laparotomy, burdened by itself with a morbidity that varies from 5 to $22 \%[6,62,63]$ and the possibility, in case of conversion, to perform a laparotomy "calibrated" to the clinical picture, in the presence of perforations from more than 24 hours, with a diameter $>1 \mathrm{~cm}$, in addition to a poor performance status and / or hemodynamic instability.

Discussion: The data in the literature agree in affirming the central role of surgery in the treatment of patients with abdominal sepsis [1-6,11-13,62], but despite the progress of the last few years the mortality of these patients remains unacceptably high (30-60\%) and more often than not more interventions are needed surgical procedures aimed at eradicating sepsis. The objectives of the surgical treatment were:

a) The timely diagnosis of sepsis.

b) The identification and elimination of all the collections.

c) The repair or removal from the peritoneal cavity of the source of contamination ne.

d) Closure of the abdominal wall without high tension

e) Careful monitoring of any septic persistence or recurrence. Control of the peritonal contamination source was obtained by resection of colonic perforation of the entire segment -ressed and the creation of an upstream enterostomy (Hartmann's intervention) which represents the most rational choice since a primary anastomosis packaged in a septic medium has a high probability of dehiscence.

Conclusion: In cases of retroperitoneal sepsis, as well as in the adequate evacuation (surgical and / or percutaneous) of the infected collections, an effective antibiotic therapy, with an adequate nutritional supply that represents the most effective therapeutic scheme, The most important success variables identified are the careful selection of patients and the availability of a medical (Intesiva therapy) and surgical team dedicated to this pathology. 


\section{Introduction}

In the last decade, attention has been paid to severe abdominal infections which, due to their severity and difficulty in treatment, cause death in 30-60\% of cases [1-6]. Despite the improvement of diagnostic techniques, selective antimicrobials, and an effective system for monitoring critical parameters, diffuse peritonitis remains a real challenge, due to the complexity and multifactorial nature of the functional deficits that characterize its decoration, both for the different answer that the single organism succeeds in giving to the treatment, the latter peculiarity that determines a difficult one. Framework of safe driving parameters, in the timing and monitoring of the therapeutic treatment as well as of the organism's response to it. the knowledge of the anatomy of the retroperitoneal space constitutes an essential support for the correct diagnostic and therapeutic approach to the infections that develop in it [2-4,62-65]. The pelvic retroperitoneal area is therefore divided into 4 spaces : prevesical (between pubis and bladder), retescerical (between bladder and rectum), presacral (between rectum and sacrum), bilateral perirectal From the etiological point of view, we can distinguish between primitive and secondary forms. In primitive retroperitoneal infections, the germs responsible are Stafilococcus Aureus strains, although streptococci [66-68], E. Coli [69-71], Proteus mirabilis [72-74], Brucellar spp (are isolated) are isolated $[75,76]$.

In secondary retroperitoneal infections are due to direct contamination by contiguous structures, mainly due to gastrointestinal diseases (Crohn's disease, diverticulitis, pancreatitis, colon cancer) or renal disease. from post-traumatic pathologies, post-operative infections, iatrogenic maneuvers (eg duodenal perforation during CPRE), coagulopathy or anticoagulant therapy, osteomyelitis. The most commonly isolated germs are Gram negative and anaerobic of gastrointestinal origin, such as $E$. Coli and Bacteroides Fragilis (1). a bacterial peritonitis,] is evaluated with a currently most used system which is the APACHE II (Acute Physiologic and Chronic Health Score) of Knaus [76-79] which has a great predictive value. In 1997 Ohmann [1] and Peritonitis Study Group proposed a new prognostic model (Prognostic Peritonitis Model, PPM), in the end identifying patients with an unfavorable outcome and a high risk of infectious complications. the classification system of the severe forms involves the evaluation of the anatomic-physiological parameters, the extension of the process, the nature of the contamination, highlighting the differences in the charge and in the bacterial contaminant stipe, the presence of associated tissue necrosis, as well as the persistence of a continuous source of contamination. Finally, these data are associated with the evaluation of the nutritional status, the immune status and the time between the pathogenic insult and the therapy. This complex data acquisition provides the surgeon with the elements to select patients who require more aggressive treatment. In this article, surgical strategies in abdominal infections due to colonic perforation with sepsis are discussed.

\section{Materials and Methods}

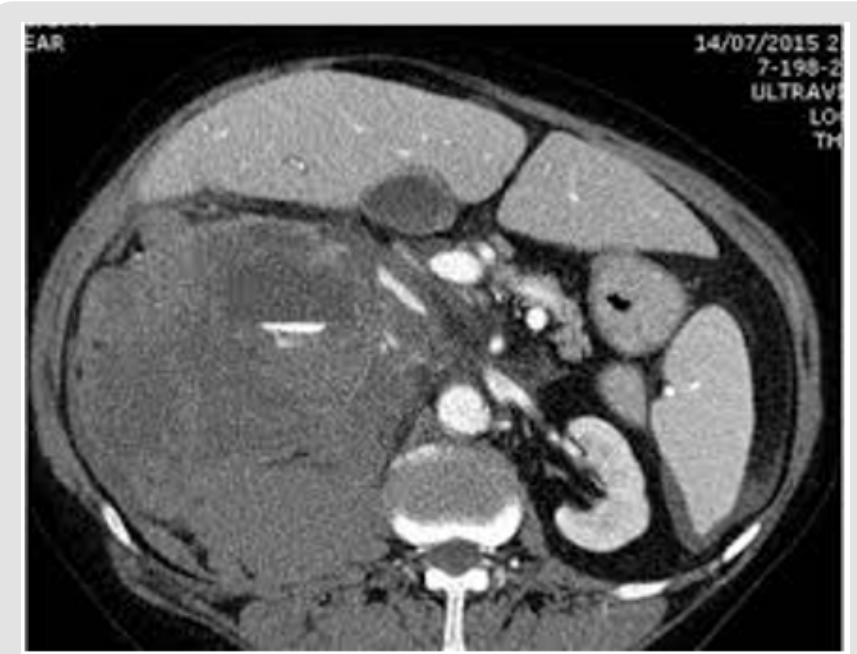

Figure 1: CT Treo Peritoneal Abscess.

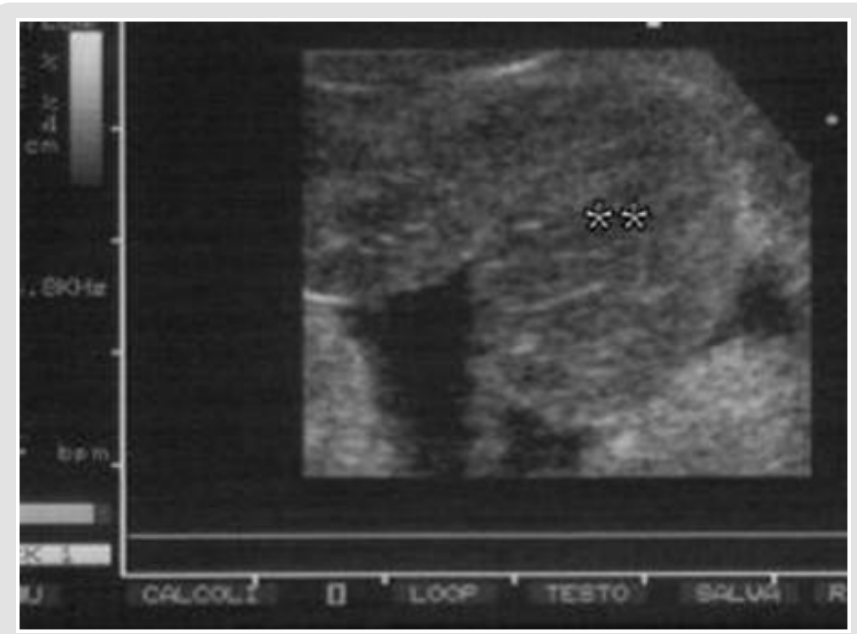

Figure 2: Echography Retroperitoneal Abscess.

The study was carried out on 12 patients from January 01.01.2015 to December 31.12.2018 in retrospective consultation of the Database and the medical records of the AOU Polyclinic University of Catania. Department of Medical Surgical Specialties II. In the selection of patients undergoing surgery for retro peritoneal intestinal perforation n 10 cases affected the colorectal, n 2 ileum cases, Patients $n 8$ were male, and the remaining 4 cases were female with an average age of 62 years [7-61] retroperitoneal infections, especially in primitive forms, have often been characterized by a considerable diagnostic delay (2weeks on average). Unspecified symptoms and non-specific signs were fever, tenderness, asthenia, leukocytosis. Only in the most advanced phases accompanied by the development of masses, and the rapid deterioration of the general conditions do they constitute an important alarm bell. In $5 \%$ of cases, the clinical onset was a full-blown septic shock with the presence of a MOF. From the diagnostic point of view, the advent of new imaging techniques has revolutionized the approach 
to retroperitoneal infections: ultrasound (Figure 2) and computed tomography, as well as having a specificity of $77 \%$, a sensitivity of $100 \%$ and a diagnostic accuracy around 88\% [74], are particularly suitable for the study of retrofascial musculature and the renal compartment (Figures 1 \& 2).

The information on the morphology and on the relationships with the adjacent structures were fundamental for the planning of the surgical strategy to adopt; of utmost importance was the taking of samples for culture tests, with the consequent administration of targeted antibiotic therapy. magnetic resonance, particularly suitable for studying the bone compartment of the retroperitoneum, was also able to make a differential diagnosis with hematomas (Figure 3). The objectives of the treatment were:

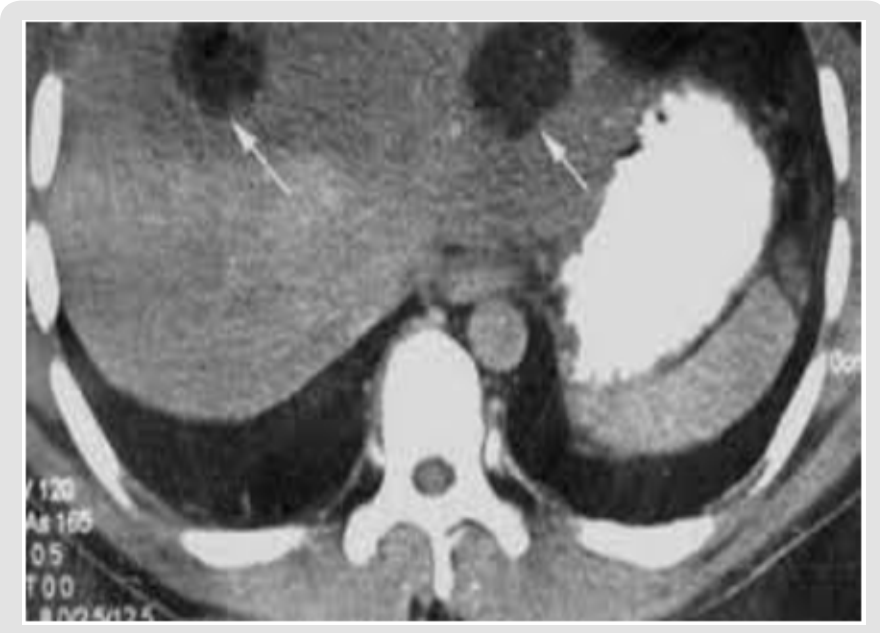

Figure 3: CT Intraparenchymal Abscess.

a) Intensive support for the restoration and stabilization of the peripheral circulation with the attainment of an adequate tissue oxygenation.

b) Adequate nutritional support, initially centralized but as soon as possible enteral.

c) Careful selection and administration of antimicrobial agents.

d) Early and aggressive surgical treatment in order to: Control the source of infection. Evacuate the prurulent material and necrotic tissues. Decompress the abdomen; recurrent infection. In the treatment of retro peritoneal infections, percutaneous drainage under radiological guidance combined with adequate antibiotic therapy was preferred as the patient's first approach. the indications to perform a laparoscopy in case of acute abdomen were:

1) The cases in which the diagnosis was not possible with less invasive methods or remain doubtful.

2) The need to obtain a rapid diagnosis (always when this is not possible with non-invasive diagnostic procedures).

3) When a diagnosis is made there is the possibility of a laparoscopic treatment.

\section{Result}

Alongside the known advantages of the minimally invasive approach (20\% of cases treated) such as less postoperative pain, shorter hospital stays, less morbidity, in cases of acute abdomen the possibility of avoiding in the first instance the laparotomy, weighed down by of a morbidity that varies from 5 to $22 \%$ and the possibility, in the case of conversion, of performing a laparotomy "calibrated" to the clinical picture, in the presence of perforations for more than 24 hours, with a diameter $1 \mathrm{~cm}$, in addition to a poor performance status and / or hemodynamic instability., were the factors that indicated for an "open" approach (9 cases equal to 80\%), "free" colic perforations rarely gave indications to a laparoscopic surgical treatment. The only cases in which colonic perforations during colonoscopy may have been indicated. Percutaneous drainage (5 cases equal to $45 \%$ ) was suitable in the approach of the abscess forms, located in the perirenal and retro fascial compartment, constituting in these cases a valid and effective alternative to more invasive surgical procedures.

Afurther advantage of percutaneous drainage was the possibility of determining, through the evacuation of most of the purulent component, an improvement in the septic picture in unstable and high-risk patients; in these conditions, more aggressive surgical therapies were performed with greater probability of success and lower operating risks. Surgery in retroperitoneal sepsis, the highly contaminating transperitoneal pathway, is not very effective, it has been avoided. The preferential routes of access have been those extraperitoneal, on the right or left side with possible muscle section. In our experience on retroperitoneal septic processes, or colonic perforations, the lombotomy sec. Fey with removal of the XI or XII ${ }^{\text {th }}$ coast allowed a wide exposure both of the upper portion of the retroperitoneum, towards the diaphragm, and of the lower one, towards the small pelvis. the evacuation of the necrotic-purulent material was complete. at the end of the intervention, they positioned themselves in the residual cavity of the drains in a sloping position both inlet and outlet; in order to carry out continuous washing to clean the back cavity. extraperitoneal access was effective, in addition to the primitive forms, also in the perirenal ones, in the flows from necrotic-hemorrhagic pancreatitis, in duodenal perforations during endoscopic maneuvers, in the form's secondary to osteomyelitis, postraumatic, from hematoma superinfection. In secondary forms of perforations - colic or ileal (Crohn's disease, diverticulitis, neoplasms, acute appendicitis) - and in intestinal anastomotic dehiscences, intraperitoneal time was required for the treatment of the primary source of infection with macrophages exposed to the action of bacterial toxins, reflects the magnitude of the peritoneal contamination, to which a higher mortality was correlated. Metabolic, respiratory and immunological imbalances constitute the pathogenetic substrate of the - organ (Multiple Organ Failure, MOF) present in $20 \%$ of the observed cases, with a sequential impairment of the functionality of different organs and systems, which undoubtedly represents the most important cause of death in patients with severe abdominal sepsis admitted 
to the wards intensive care. In an attempt to avoid the unfavorable outcome by correcting the hemodynamic response and supporting the function of the various organs, an adequate nutritional regime was introduced, initially parenteral but as soon as possible enteral, aimed at satisfying the high energy requirements and reduce the effects of calorie-protein malnutrition quickly established.

On average after 20 days it was possible to replace the parenteral with the enteral one which has an important role in maintaining the integrity of the barrier and the intestinal immune system the diet was enriched with arginine, glutamine and omega-3 fatty acids, which represent important factors of trophism of the intestinal mu-thing. in the therapeutic options the spectrum of the various antibiotics, the dosage and the modalities of administration, the drug-dynamics, and above all their effectiveness in the comparisons of the germs more often involved in the abdominal infectious process was taken into consideration. The choice (Table 1) took into account the clinical characteristics of the individual patient, of the pathology leading to abdominal sepsis, also taking into consideration that the possible presence of resistant germs and the potential side effects of anti-microbials.

Table 1: Scheme of empirical therapy in severe peritonitis.

\begin{tabular}{|c|c|}
\hline Antibiotic & Dosages \\
\hline Metronidazole $500 \mathrm{mg}$ e.v. & $\begin{array}{c}\text { Every } 6 \mathrm{~h}+\text { Cephalosporins of } 3^{\text {rd }} \\
\text { gen Variable depending on the } \\
\text { drug }\end{array}$ \\
\hline $\begin{array}{c}\text { Amoxicillin / ac. clavulanico2,2 } \\
\text { g e.v }\end{array}$ & Every 8 \\
\hline Piperacillin / tazobactam 4.5 g e.v & Every $8 \mathrm{~h}$ \\
\hline Fluoroquinolone & S Variable depending on the drug \\
\hline Imipenem 500 mg e.v & Every $6 \mathrm{~h} / 1 \mathrm{~g}$ every $8 \mathrm{~h}$ \\
\hline Meropenem $1 \mathrm{~g}$ e.v & Every $8 \mathrm{~h}$ \\
\hline Tigecycline + ev & $\begin{array}{l}\text { Anti-Pseudomonas drug } 100 \mathrm{mg} \\
\text { e.v. the } 1 \text { st dose then } 50 \mathrm{mg} \text { e.v. } \\
\text { every } 12 \mathrm{~h}\end{array}$ \\
\hline Ceftriaxone2 g e.v & Every $24 \mathrm{~h}$ \\
\hline Ceforaxime $2 \mathrm{~g}$ e.v & Every 8 hours \\
\hline Cefepime2 g e.v & $\begin{array}{c}\text { Every } 12 \mathrm{~h}+\text { Metronidazole } 500 \mathrm{mg} \\
\text { e.v. every } 6 \mathrm{~h}\end{array}$ \\
\hline
\end{tabular}

\section{Discussion}

The literature data agree in affirming the central role of surgery in the treatment of patients with abdominal sepsis [80-86], but despite the progress of recent years mortality of these patients it remains unacceptably high (30-60\%) and more often than not more surgical interventions aimed at eradicating sepsis are required. The objectives of the surgical treatment are:

a) The timely diagnosis of sepsis.

b) The identification and elimination of all the collections.

c) The repair or removal from the peritoneal cavity of the source of contamination.

d) Closure of the abdominal wall without high tension. e) Careful monitoring of any septic persistence or recurrence [87-89,7-9] The control of the peri-tonal source of contamination is was obtained by the resection of colonic perforation of the interested segment and the creation of an upstream enterostomy (Hartmann's intervention which represents the most rational choice since a primary anastomosis packaged in a septic medium has a high probability of dehiscence [10-14].

A different attitude was instead adopted if the lesion is dependent on the small intestine: after the re-section of the perforated tract (also considering the time elapsed between the onset of the lesion and laparotomy,) it was possible to package a direct anastomosis, with a low risk of dehiscence [15-19].The direct suture represents a choice between therapists [20-25]. Linked to the complete cleansing of the abdominal cavity from the spilled substances (bile, enteric juice, food, faeces) and from the branches of fibrin, with intra-operative pe-ritoneal lavage [26-30]. in order to reduce the quantity of bacteria and foreign substances, without interfering in the local defense mechanisms [31-35].

With the addition of antibiotics and antiseptics to the washing solution they do not improve the results in patients receiving an appropriate systemic antimicrobial treatment [36-40]. Eradicating the source of sepsis with the intervention represents therefore also in our experience the central moment of the therapy [41-45] the need to carry out further interventions significantly reduces the survival rate: This shows in our opinion how the complete cleansing of the cavity abdominal prurulent material represents the therapeutic pivot in these patients the important role of surgery in breaking the vicious circle that characterizes the natural history of sepsis [46-51] is represented by the most used strategies which are: a) relaparotomy b) continuous postoperative peritoneal lavage c) open surgical wound (laparostomy). Codest relaparotomy are technically more difficult, burdened by high morbidity The use of relaparotomy [52-56], in which the new surgical exploration is carried out when indicated by the instrumental and/or clinical diagnostic data, implies, a surgical rescue attempt when by now the specific defense mechanisms of the patient are severely worn down, with imminent appearance of MOF [ 57-61]. In these cases, the chances of survival are low, not exceeding 24\% [90-95]. Clinical studies have shown that the technique of continuous washing of the peritoneal cavity through inlet and outlet drains, repeated for 4-72 hours [96-101]. there is no evidence that there are any beneficial harmful effects of irrigation against which this type of treatment was limited only to cases of severe acute pancreatitis [102-112] carried out only in initial infectious processes with confined collections or whose short-term results were not significant [113-116].

\section{Conclusion}

In cases of retroperitoneal sepsis, as well as in the adequate evacuation (surgical and/ or percutaneous) of the infected collections, an effective antibiotic therapy, with an adequate nutritional supply represents the most effective therapeutic scheme. In the presence of complications, especially in critical 
patients with high score APACHE II. although we do not yet have safe guide parameters in defining the extent of infection in the timing and in the selection of patients who require more aggressive and early surgical treatment in order to control the source of infection. The most important success variables are the careful selection of patients and the availability of a medical (Intesiva therapy) and surgical team dedicated to this pathology, which due to its complexity and multi-factorial nature represents a very demanding challenge.

\section{Acknowledgement}

None.

\section{Conflict of Interest}

\section{No conflict of interest.}

\section{References}

1. Hau T, Ohmann C, Wolmershauser H. Wacha H, Yang Q (1995) Planned relaparotomy vs relaparotomy on demand in the treat-ment of intraperitoneal infections. Arch Surg 130(11): 1193-1197.

2. Teichmann W, Wittmann DH, Andreone A (1986) Sche-duled reoperations (Etappenlavage) for diffuse peritonitis. Arch Surg 121(2): 147-152.

3. Van Goor H, Hulsebos RO, Bleichrodt RP (1997) Compli-cations of planned relaparotomy in patients with severe general peritonitis. Eur J Surg 163(1): 61-66

4. Reith HB (1997) Peritonitis therapy today: surgical management and adjuvant medical therapies. Langenbecks Arch Chir 382 (Suppl.1): S14-S17.

5. Wittmann DH, Walker AP, Condon RE (1993) Peritonitis, intraabdominal infection, and intra-abdominal abscess. In: Schwartz SL, Shires GT, Spencer FC (Eds.), Principles of Surgery, $6^{\text {th }}$ (edn.). Mc Graw Hill, New York, USA. pp: 1449-1484.

6. Rotstein OD, Simmons RL (1994) Peritonitis and intraabdominal abscess. In: Barie PS Shires GT (Eds.), Surgical In-tensive Care, Little Brown \& Co, Boston, USA.

7. Schein M, Assalia A, Bachus H (1994) Minimal antibiotic therapy after emergency abdominal surgery: a prospective study. Br JSurg 81(7): 989991.

8. Wilson SE (1997) Meropenem in the treatment of intra-abdominal infection: review of the clinical trials. Adv Ther 14: 110-115.

9. Krepel CJ, Gohr CM, Edmiston CE, Condon RE (1995) Surgical sepsis: constancy of antibiotic susceptibility ofcausative organisms. Surgery 117(5): 505-509.

10. Schein M, Wittmann DH, Lorenz W (1996) Forum statement: A plea for selective and controlled post-operative antibiotic administration. Eur J Surg 576 (suppl): 66-69.

11. Schein M (1992) Management of severe intra-abdominal infection. Surg Annu 201: 47-68.

12. Anderson ID, Fearon KCH, Grant IS (1996) Laparotomy for abdominal sepsis in the critically ill. Br. J. Surg 83(4): 535-539.

13. Van Gore H (1997) Surgical treatment of severe intraabdomina infection. Hepato-Gastroenterology 44(16): 975-981.

14. Farthmann EH, Schöffel U (1990) Principles and limitation of operative management of intraabdominal infections. World J Surg 14(2): 210-217.

15. Polk HC, Fry DE (1980) Radical peritoneal debridement for established peritonitis: the result of a prospec-tive randomized clinical trial. Ann Surg 192(3): 350-355.
16. Schein M, Saadia R, Decker GG (1988) Intraoperative peritoneal lavage. Surg Gynecol Obstet 166(2): 187-195.

17. Pollok AV (1993) Reviews on wound and peritoneal lava-ge: concepts, experiments and clinical trials for decision making. Theor Surg 8: 103110.

18. Ferraris VA (1984) Exploratory laparotomy for potential abdominal sepsis in patients with multiple organ failure. Arch Surg 118(10): 11301133.

19. Hinsdale JF, Jaffe BM (1984) Re-operation for intraabdominal sepsis. Indications and results in modern criti-cal setting. Ann Surg 199(1): 3136.

20. Norton LW (1985) Does drainage of intraabdominal pusreverse multiple organ failure? Am J Surg 149(3): 347-350.

21. Stephen M, Loewenthal J (1985) Continuing peritoneal lavage in highrisk peritonitis. Surgery 85(6):603-606.

22. Silenas R, O Keefe P, Gelbart S (1983) Mechanical effectiveness of closed peritoneal irrigation in peritonitis. Am J Surg 145: 371-373.

23. OBrien PE, Tait N, Bushell M (1987) Management of dif-fuse peritonitis by prolonged postoperative peritoneallavage. Aus NZJ Surg 57(3): 181184

24. Leiboff AR, Soroff HS (1987) The treatment of generali-zed peritonitis by closed postoperative peritoneal lava-ge. Arch. Surg 122(9): 1005-1010.

25. Buanas TA, Amndersen GP, Jacobsen U, Nygaard K (1991) Perforated appendicitis with generalized peritonitis. Prospective, randomized evaluation of postoperative peritoneal lavage. Acta Chir 157(4): 277279.

26. Andrea Cavallaro, Giorgio Maria Paolo Graziano, Marco Cavallaro,Antonino Graziano (2015) The Stent Evolution in Colo - Rectal Emergencies. Peertechz Journal of Surgery and Surgical Research 1(3): 045-048.

27. Andrea Cavallaro, Giorgio Maria Paolo Graziano, Marco Cavallaro,Antonino Graziano(2015)The Neuroendocrine Cancer. Personal Comments and Operational Remarks. J Surg Surgical Res 1(3): 053-058.

28. Imhof M (1991) Errors in lavage therapy in diffuse peritonitis. Zentralbl. Chir 166: 187-195.

29. Schein M, Cecelter G, Freinkel W, Gerding H (1990) Peritoneal lavage in abdominal sepsis: a controlled clinicalstudy. Arch Surg 125(9): 11321135.

30. Edminston CE, Goheen MP, Kornhall S, Jones FE, Condon RE (1990) Fecal peritonitis: microbial adherence to serosal me-sothelium and resistence to peritoneal lavage. World J Surg 14(2): 176-183.

31. Giorgio Maria Paolo Graziano,Marco Cavallaro,Antonino Graziano (2016) The Familiary Adenomatous Polyposis. A Difficult Problem, Between Prevention and Treatment. Peertechz Journal of Surgery and Surgical Research 2(1): 005 -009.

32. Giorgio Maria Paolo Graziano,Marco Cavallaro, Antonino Graziano (2016) Clinical And Molecular Anatomy of GastroIntestinal Stromal Tumor. International Journal of New Technology and Research 2(4): 110-114.

33. Pederzoli P, Bassi C, Vesentini S, Girelli R, Cavallini G, et al. (1990) Retroperitoneal and peritoneal drainage and lavage in the treatmentof severe necrotizing pancreatitis. Surg Gynecol Obstet 170(3): 197-203.

34. DEgidio A, Schein M (1991) Surgical strategies in the pancreatic necrosis and infection. Br J Surg 78(2): 133-137.

35. Pederzoli P, Bassi C, Falconi M (1996) La necrosec-tomia ed il drenaggio a perfusione continua nella necro-si acuta pancreatica grave. Arch Atti SIC 3: 186-193.

36. Farkas G, Marton J, Mandi Y, Szederkenyi E (1996) Surgical strategy and management of infected pancreatic necrosis. Br J Surg 83: 930-933. 
37. Champault G, Magnier M, Psalmon F, Patel JC (1979) Di-scussion en cours: la non-fermeture parietale dans la chi-rurgie iterative des peritonites. Chirurgie 105: 866-869.

38. Hay JM, Duchatelle P, Elman A (1979) Les ventreslaisses ouverts. Chirurgie 105: 508-510.

39. Hollender LF, Bur F, Schwenck D, Pigache P (1983) Das“'Offengeniassene abdomen" Technik, indication und resultate. Chirurgie 54: 316-119.

40. Giorgio Maria Paolo Graziano, Marco Cavallaro, Antonino Graziano (2016) Treatment Therapies in Renal Cell Carcinoma in elderly: A Descriptive Analysis.International Multispecialty Journal of Health (IMJH): 2(5).

41. Giorgio Maria Paolo Graziano,Marco Cavallaro,Antonino Graziano (2016) Which Therapeutic Treatment in Gastric Lymphoma, World Journal of Research and Review 2(6): 06- 09.

42. Giorgio Maria Paolo Graziano, Marco Cavallaro, Antonino Graziano (2016) On Traumatic Lesions of The Pancreas. World Journal of Research and Review 2(6): 24-28.

43. Giorgio Maria Paolo Graziano, Marco Cavallaro, Antonino Graziano (2016) Renal Ureteroscopy Treatment of Kidney and Bladder Stones. International Journal of New Technology and Research 2(5):135-138.

44. Giorgio Maria Paolo Graziano, Marco Cavallaro, Antonino Graziano (2016) Vascular Thoracic Fibrous Adipose Tissue (new disease). J Pharm Biomed 06 (07): 419-424.

45. Giorgio Maria Paolo Graziano, Marco Cavallaro, Antonino Graziano (2016) Which Treatment for Abdominal Trauma in Pediatric Age International Journal of New Technology and Research (IJNTR) 2(6): 24-28

46. Giorgio Maria Paolo Graziano,Marco Cavallaro, Antonino Graziano (2016) Early Epithelial Ovarian Carcinoma Treatment International Journal of New Technology and Research (IJNTR) 2(5): 69-74.

47. Giorgio Maria Paolo Graziano, Marco Cavallaro, Antonino Graziano (2016) Clinical and Molecular Anatomy of Gastrointestinal Stromal Tumors (GIST) International Journal of New Technology and Research (IJNTR) 2(4)110-114.

48. Giorgio Maria Paolo Graziano, Marco Cavallaro, Antonino Graziano (2016) Which treatment in cystic tumors of the pancreas: conservative or resection. International Journal of Current Advanced Research 5(8): 1190-1198.

49. Giorgio Maria Paul Graziano (2016) Diagnostic and therapeutic in the intestinal duplication.International Journal of Recent Scientific Research 7(8): 13000-13003.

50. Richards WO, Scovill W, Shin B, Reed W (1983) Acute renal failure associated with increased intra-abdominal pres-sure. Ann. Surg 197(2): 183-187.

51. Duff JH, Moffat J (1981) Abdominal management by leaving abdomen open. Surgery 90(4): 774-776.

52. Maetani S, Tobe T (1981) Open peritoneal drainage as effective treatment of advanced peritonitis. Surgery 90(5): 804-809.

53. Giorgio Maria Paolo Graziano, Marco Cavallaro, Antonino Graziano (2019) Analysis of Early Relaparotomy After Gastrointestinal Surgery', International Journal of Current Advanced Research 08(02): 1756217566.

54. Giorgio Maria Paolo Graziano, Marco Cavallaro, Antonino Graziano (2019) perforated duodenal events post CPRE with VBPstent which procedure. International Journal of Current Advanced Research 8(3): 17962-17968.

55. Giorgio Maria Paolo Graziano, Marco Cavallaro, Antonino Graziano (2019) Management of the Bile Duct after Iatrogenic Iniury. Int J Recent Sci Res 10(06): 32826-32830.

56. Wouters DB, Krom RAF, Sloof MJH, Kootstra G Kuijjer J (1983) The use of Marlex mesh in patients with generalized peritonitis and multiple organ system failure. Surg Gynecol Obstet 156(5): 609-617.
57. Hedderich GS, Wexler MJ, McLean APH, Meakins JL (1986) The septic abdomen: open management with Marlex mesh with a zipper. Surgery 99(4): 399-407.

58. Walsh GL, Chiasson P, Hedderich G, Wexler MJ,Meakins JL (1988) The open abdomen. Surg Clin North Am 68(1): 25-40

59. Giorgio Maria Paolo Graziano, Marco Cavallaro, Antonino Graziano (2017) Congenital Anomalies of The Kidney and Urinary Tract Neoplasms and in the Elderly. Int J Adv Res 5(3): 265

60. Graziano Giorgio Maria Paul and Anthony Di Cataldo (2017) Complications in Laparoscopic Cholecystectomy International Journal of Current Advanced Research 6(05): 3855-3859.

61. Graziano Giorgio Maria Paul and Anthony Di Cataldo (2017) Lithiasis In Urinary Diversions or Post Prostatectomy. International Journal of Recent Scientific Research 8: 16357-16363.

62. Wittmann DH, Schein M, Condon RE (1996) Management of secondary peritonitis. Ann Surg 224(1): 10-18.

63. Elebute EA, Stoner HB (1983) The grading of sepsis. Br J Surg 70(1): 29-31.

64. Dominioni L, Dionigi R, Zanello M, Monico R, Cremaschi R, et al. (1987) Sepsis score and acute-phase protein response as predictors of outcome in septic surgical patients. Arch Surg 122(2): 141-146.

65. Bohnen J, Boulanger M, Meakins JL, Mc Lean AP (1983) Prognosis in generalized peritonitis: relation to cause andrisk factors. Arch Surg 118(3): 285-290.

66. Wacha H, Linder MM, Feldmarm U (1987) Mannheim peritonitis index prediction of risk from peritonitis: construction of statistical and validation andempirically based index. Theor Surg pp. 169-177.

67. Billing A, Frohlich D, Schildberg W (1994) The Peri-tonitis Study Group. Prediction of outcome using the Mannheim peritonitis index in 2003 patients. Br J Surg 81(2): 209-213.

68. Meakins JL, Solomkin JS, Allo, Patchen Dellinger E, Richard J Howard, et al. (1984) A pro-posed classification of intra-abdominal infections. Arch Surg 119(12): 1372-1378.

69. Dellinger EP, Wertz MJ,Jonathan L Meakins, Joseph S Solomkin, Richard J. Howard, et al. (1985) Surgi-cal infection stratification sistem for intraabdominal infection. Arch Surg 120(1): 21-29.

70. Knaus WA, Draper EA, Wagner DP, Zimmerman JE (1985) APACHE II: a severity of disease classificationsystem. Crit Care Med 13(10): 818-829.

71. Nyström PO, Bax R, Dellinger EP, Lorenzo Dominioni William A. Knaus, et al. (1990) Proposeddefinitions for diagnosis, severity scoring, stratifications. And outcome for trials on intra-abdominal infection. World J Surg 14(2): 148-158.

72. Ohmann C, Wittmann DH, Wacha H (1993) Peritonitis Study Group: Prospective evaluation of prognostic scoring systems in peritonitis. Eur J Surg 159: 267-274.

73. Schein M, Hirshberg A, Hashmonai M (1992) Current sur-gical management of severe intraabdominal infection. Surgery 112(3): 489496.

74. Ohmann C, Yang Q Hau T (1997) Prognostic Mo-delling in peritonitis. Eur J Surg 163(1): 53-60.

75. Parrillo JE (1993) Pathogenic mechanisms of septic shock.New Engl J Med 328(20): 1471-1477.

76. Goris RJA, Te Boekhorst TPA, Nuytinck JKS, Gim-brere JSF (1985) Multiple organ failure: generalized autode-structive inflammation. Arch Surg 120(10): 1109-1115.

77. Cerra FB (1990) Multiple organ failure syndrome: patterns and effects of current therapy. In Vincent J.L. ed. Update in Intensive Care and Emergency Medicine. Berlin: Springer Verlag p. 22-31.

78. Mc Lauchlan GJ, Anderson ID, Grant IS, Fearon KCH (1995) Outcome of patients with abdominal sepsis trea-ted in an intensive care unit. $\mathrm{Br} \mathrm{J}$ Surg 82(4): 524-529. 
79. (1995) SIMPE: Linee guida per l'impiego della nutrizioneparenterale ed enterale: Terapia intensiva. RIMPE 13 (S-2): 39-42.

80. Heyland DK, Cook DJ, Guyatt GH (1993) Enteral nutrition in critically ill patients: a critical review of evidence. Intensive Care Med 19(8): 435442

81. Bower RH, Ceraa FB, Bershadsky B, Licari JJ, Hoyt DB, et al. (1995) Early enteral administration of a formula (Impact) supplemented with arginine, nucleotides, and fish oil in intensive care unit patients. Results of a multicenter, prospective, randomized clinical trial. Crit Care Med 23(3): 436-439.

82. Mosdel DM, Morris DM, Voltura A, Pitcher DE, Twiest MW, et al. (1991) Anti-biotic treatment for surgical peritonitis. Ann Surg 214(5): 543-549.

83. Wittmann DH (1991) Intraabdominal infections: pathophysiology and treatment. M Dekker, Inc, New York, USA.

84. Condon RE (1996) Microbiology of intraabdominal infec-tion and contamination. Eur J Surg 576 (suppl): 9-12.

85. Bohnen JMA, Solomkin JS, Dellinger EP, Bjornson HS, Page CP (1992) Guidelines for clinical care: anti-infective agents for intra-abdominal infection: A Surgical Infection Society policy statement. Arch Surg 127(1): 83-89.

86. Nathens AB, Rotstein OD (1996) Antimicrobial therapyfor intrabdominal infection. Am J Surg 172 (suppl 6A): 1-6.

87. Wittmann DH, Bergstein JM, Frantzides CT (1991) Cal-culated enpiric antimicrobial therapy for mixed surgicalinfections. Infection 19(suppl 6): $345-350$.

88. Gorbach SL (1993) Intra-abdominal infections: state of the art clinical article. Clin Infect Dis 17(6): 961-967.

89. Schein M, Karban A, Assalia A, Eldar S (1994) Current attitudes concerning the duration of antibiotic therapy following operation for abdominal contamination and infection: results of an Israeli national survey. Theor Surg 9: 160-164.

90. Graziano Giorgio Maria Paul, Anthony Di Cataldo (2017)) Papillary Bladder Tumor . International Journal of Recent Scientific Research 8: 18485-18490.

91. Graziano Giorgio Maria Paul, Anthony Di Cataldo (2017). Role of Genetic Mutations in The Diagnosis of Gallbladder Neoplasms, International Journal of Recent Scientific Research 8: 20908-20913.

92. Penninckx FM, Kerremans RPJ, Lauwers PM (1990) Planned relapatomies in the surgical treatment of seve-re generalized peritonitis. Word J Surg 14: 218-226.

93. Garcia-Sobrido JL, Tellado JM, Christou NW (1988) Treatment of severe intra-abdominal sepsis and/or necrotic foci by an "open abdomen" approach. Arch Surg 123:155-156.

94. Wittmann DH, Aprahamian C, Bergstein JM (1990) Etappenlavage advanced diffuse peritonitis managed by planned multiple laparotomies utilizing zippers. Slide fastener and velcro analogue for temporary abdominal closure. World J Surg 14(2): 218-226.

95. Giorgio Maria Paolo Graziano, Antonio Di Cataldo, Antonino Graziano (2017) Single Accessed Gallbladder Surgery. International Journal of Recent Scientific Research 8(8): 19359-19362.

96. Giorgio Maria Paolo Graziano., Antonio Di Cataldo and Antonino Graziano (2017) The Use of Bar in Colorectal Surgery in the Elderly (If 6.860). International Journal of Recent Scientific Research 8: 19950-19954.

97. Giorgio Maria Paolo Graziano, Antonio Di Cataldo and Antonino Graziano (2017) The antibiotic is needed in clean surgery? (IF 7,383). International Journal of Recent Scientific Research 8: 22339-22342.

98. Giorgio Maria Paolo Graziano, Antonio Di Cataldo, Antonino Graziano (2018) Which Treatment For tpo (Primitive Occult Tumors). Int J Recent Sci Res 9(1): 23436-23439
99. Giorgio Maria Paolo Graziano, Antonio Di Cataldo, Antonino Graziano (2018) Local recurrences after ultra-low resection of therectum (IF 7,383). International Journal of Recent Scientific Research pp. 2411924124 .

100. Giorgio Maria Paolo Graziano, Antonio Di Cataldo, Antonino Graziano (2018) Staging criteria in the local treatment of neoplasms the rectum. International Journal of Recent Scientific Research 10(04).

101. Giorgio Maria Paolo Graziano, Antonio Di Cataldo, Antonino Graziano (2018) The radical anal trans excision in the initial neoplasm of the rectum. International Journal Recent Sci Res pp. 2413-24017

102. Giorgio Maria Paolo Graziano, Antonio Di Cataldo, Antonino Graziano (2018) The "Tailored surgery", in the preservation of the anal sphincter in the tumor of the rectum. International Journal of Current Research 10(04): 67675-67681.

103. Giorgio Maria Paolo Graziano, Antonio Di Cataldo, Antonino Graziano (2018) Staging end preparation of the patient in rectal surgery. Int J Recent Sci Res 9(3): 24995-24999.

104. Giorgio Maria Paolo Graziano, Antonio Di Cataldo, Antonino Graziano (2018) the surgical strategy in therectal resection. Int J Recent Sci Res 9(3): 24875-24880.

105. Giorgio Maria Paolo Graziano, Antonio Di Cataldo, Antonino Graziano (2018) functional results for ulta low resection of the rectum. Int J Recent Sci Res 9(3): 24745-24749

106. Giorgio Maria Paolo Graziano, Antonio Di Cataldo, Antonino Graziano (2018) Pelvic linfectomy in rectal surgery. Int J Recent Sci Res 9(3d): 24745-24749

107. Giorgio Maria Paolo Graziano, Antonio Di Cataldo, Antonino Graziano (2018) Current Prognostic Factors in Colorectal Cancer. International Journal of Recent Scientific Research 9: 25375-25380.

108. Giorgio Maria Paolo Graziano, Antonio Di Cataldo, Antonino Graziano (2018) the manual anastomosis rectal colon today. International Journal of Recent Scientific Research 9: 25571-25575.

109. Giorgio Maria Paolo Graziano, Antonio Di Cataldo, Antonino Graziano (2018) Which laparoscopic treatment in pancreatic pathology. International Journal new technology and research 4(6): 62-67.

110. Giorgio Maria Paolo Graziano, Antonio Di Cataldo, Antonino Graziano (2018) The evaluation of pulmonary solid nodulesfor resection surgeryInternational Journal new technology and research 4(6): 5861

111. Schein M, Wittmann DH, Aprahamian C, Condon RE (1995) Abdominal compartment syndrome: the physiological and clinical consequences of elevated intra-abdo-minal pressure. J Am Coll Surg 180(6): 745-753.

112. Christou NV, Barie PS, Dellinger EP, Waymack JP, Stone HH (1993) Surgical Infection Society intra-abdominal infection study:prospective evaluation of management techniques and outcome. Arch Surg 128(2): 193-199.

113. Schein M (1991) Planned reoperations and open management in critical intra-abdominal infections: prospective experience in 52 cases. World J Surg 15(4): 537-545.

114. Wittmann DH, Bansal N, Bergstein JM, JR Wallace, Wittmann MM, et al. (1994) Staged abdominal repair compares favorably with conventional operative therapy for intra-abdominal infectionswhen adjusting for prognostic factors with a logistic model. Theor Surg 9: 201-207.

115. Andrus C, Doering M, Herrmann VM, Kaminski DL (1986) Planned reoperation for generalized intrabdominal infection. Am J Surg 152: 682-686.

116. Neijenhuis P, Muckart D (1995) Planned relaparotomy: afutile procedure? Curr Opin Surg Infect 3: S28. 
ISSN: 2574-1241

DOI: $10.26717 /$ BJSTR.2019.21.003581

Graziano Giorgio Maria Paolo. Biomed J Sci \& Tech Res

(c) (i) This work is licensed under Creative

Submission Link: https://biomedres.us/submit-manuscript.php

$\begin{array}{ll}\text { BIOMEDICAL } & \text { Assets of Publishing with us } \\ \text { RESEARCHES } & \text { - Global archiving of articles } \\ & \text { - Immediate, unrestricted online access } \\ & \text { - Rigorous Peer Review Process } \\ \end{array}$

